\title{
Parents' meetings in two neonatal units: a way of increasing support for parents
}

\author{
JANE DAMMERS, VAL HARPIN
}

\begin{abstract}
For a combined total of three years meetings have been held regularly on two neonatal units for parents with infants requiring neonatal intensive care. These meetings give parents an opportunity to meet each other and members of staff in an informal atmosphere in the hope that mutual support will be gained. Initial assessment shows that the parents gain confidence in their ability to look after such small babies. The staff have gained a greater insight into the parents' anxieties and problems and changes have been made in the procedures on these units. If new insight is to result in changes that benefit the parents their views must be made known and taken into account when policy decisions are made.
\end{abstract}

\section{Introduction}

Parents whose infants require special care usually have little knowledge of the problems of prematurity or the confusing equipment required for treatment. In an alien environment, where doctors, nurses, and machines take over the care of their

St George's Hospital, London

JANE DAMMERS, $\mathrm{MB}, \mathrm{DCH}$, senior house officer, neonatal paediatrics (current appointment: clinical medical officer, West Lambeth Health Authority, London)

Department of Neonatal Medicine and Surgery, City Hospital, Nottingham

VAL HARPIN, MRCP, research fellow infant, parents feel not only acutely anxious but also superfluous. Understandably many find it difficult to relate to their baby, which may be a major factor in the increased incidence of child abuse ${ }^{1}$ and non-organic failure to thrive ${ }^{23}$ among infants discharged from neonatal units.

Parents with babies in a neonatal unit share many common experiences. Can they give each other support? We report on parents' meetings in two neonatal units. We think that these meetings are useful, and we would encourage other units to consider a similar venture.

\section{Aims of the meetings}

Weekly parents' meetings were set up to:

(1) Give parents more opportunity to get to know each other and, by sharing common experiences, decrease anxiety and increase confidence.

(2) Enable parents to teach staff about their experiences and suggest improvements.

(3) Discuss practical problems and worries.

(4) Identify parents needing more individual help.

\section{Structure of the meetings}

Both neonatal units are busy regional referral centres. Of the total number (688) of admissions at City Hospital, $35 \%$ were from a peripheral hospital, as were $45 \%$ of the 251 babies admitted to St George's Hospital in 1981.

Meetings began at St George's in October 1980, as a result of a conversation with two parents who thought that more contact with other parents would have been helpful during their baby's threemonth stay in the unit. In Nottingham meetings began on a two-month trial basis in March 1981 and were then evaluated. Meetings have continued in both units ever since.

The meetings are held on weekday evenings in informal sitting 
rooms with tea and coffee provided. All parents are given written and verbal invitations, and the meetings are publicised on posters. Discussion develops from whatever points parents raise; there are no set topics. Detailed consideration of individual management problems is avoided, and meetings are not intended to be a "therapy group" in the psychiatric sense.

At each centre six professionals run the meetings. They include neonatal sisters, junior doctors, social workers, and a community midwife. Two or three attend each week and keep a written record. They also meet separately to discuss the running of the group and specific issues raised by the parents. Consultants do not attend the meetings but have given their support throughout.

\section{Results}

On average, five parents attend but this varied from none to 12 . In both centres about half of the parents whose baby was in the unit for more than two weeks came to at least one meeting. Some came every week during their infant's stay.

Initial assessment of the group in Nottingham by a confidential written questionnaire showed that parents who attended the meetings found them supportive and thought that they should continue in the same format. This was confirmed by a similar questionnaire to a sample of parents at St George's. We specifically asked whether the meetings provoked anxiety; no parent found that they did.

\section{COMMON SUBJECTS DISCUSSED IN THE MEETINGS}

Parents found the meetings a useful forum to discuss a wide range of subjects such as the following.

\section{Antenatal problems}

Many women had had problems with pregnancies and spent long days on the antenatal ward with little to occupy them except their anxieties about the outcome of their pregnancy. Those who had visited the neonatal unit and talked to paediatric staff found this reassuring. Others had not had the opportunity to do so.

Some women had had normal pregnancies until they went into premature labour unexpectedly. They described their bewilderment at being rushed into hospital and their disorientation during long hours in the labour ward attached to drips and monitors: "I did not know if it was day or night." "My head was throbbing from the effect of the salbutamol drip and I could not recognise people coming in and out of the room." Some women said that they were not told enough about what was happening to them or had been given conflicting views. Both parents often felt physically and mentally unprepared for the birth: "I feel that I have had a major operation (caesarean section) but not that I have had a baby." "I should have had another two months to get used to being a father."

\section{First postnatal days}

Most mothers had had only a brief glimpse of their baby before it was whisked away to the neonatal unit. Fathers, who usually first saw the baby in the unit, spoke of difficulties in telling all that they had been told about their baby's condition and treatment to mothers on the postnatal ward. It was often several hours or even days before the mother saw the baby again. Some women did not want to know, "no news is good news." This increased the father's distress. Polaroid photographs taken of all the babies in both units were helpful but could be misleading; it was important to give an idea of scale by placing a pen or something similar next to the baby. Nothing could compensate for the shock of seeing their tiny premature infant for the first time. Mothers described feelings of guilt and inadequacy at having produced a baby whom they perceived as "rat-like" or "disappointing." Parents talked of their ambivalence towards forming an attachment, expecting the baby to die; "I don't feel as though the thing in the incubator is anything to do with my pregnancy."

Initially the equipment and noisy alarms were daunting but soon became reassuring. Parents particularly disliked the radiant heater "grill pan" and anything around the baby's face. They observed changes closely; the weight chart assuming particular importance. Errors and malfunctioning equipment did not escape their notice, and it was difficult for both parents and staff to come to terms with this.

\section{Postnatal wards}

Being surrounded by other women with their healthy full-term infants could be extremely upsetting, especially if your baby was seriously ill in the neonatal unit, and many women preferred to be in a single cubicle or with other mothers of premature babies. "The feelings of hopelessness and the fears just come and you can't stop them. The only way I felt better was to go and see my baby and then I would feel good for a time. The other mothers wished your baby was with you but they were so full of their own babies. All you do is look on like someone outside."

The heat, noise, and lack of privacy in the unit made visiting tiring and frustrating. Many women had to come down from the postnatal wards in a chair; they were several floors above the neonatal units in both hospitals. They did not like to bother staff and had to be on the ward for meals and doctors' rounds. This meant that they often did not see their baby when they wished.

\section{Involvement in the baby's care}

Parents spoke of being afraid to touch, hold, feed, and change their baby; once they overcame their initial anxiety this contact became important; "it helps us to feel the baby belongs to us and not to the staff." Providing breast milk was seen as an important contribution to their baby's care, but mothers did find that expressing milk could be difficult, painful, time consuming, and, at times, embarrassing. Expert help was much appreciated but not always easily available.

\section{The mother goes home}

Going home could be distressing. Many women felt that they were abandoning their infant. They had to adjust to being a "mother" without a baby to show their relatives and friends at home. Parents emphasised that they wished to be kept fully informed of their infant's progress but said that they often feared the information; "my husband always phones up in the morning, I can't do it or even bear to be in the same room." Being able to visit or telephone at any time was important. Visiting could be tiring and expensive and was particularly demanding when there were other children. Parents thought it important that siblings were made welcome, had a play area, and were allowed to bring a few of their own toys. It was helpful if other relatives and close friends could visit too. Once initial problems were settled parents felt proud of their infants and wanted to share them with their relatives and friends.

\section{Transfer to a peripheral hospital}

Infants of mothers who initially booked at a peripheral hospital were transferred back when they no longer needed intensive care. This sometimes caused anger and distress. Some parents had been told that the peripheral hospital could not meet the needs of very premature babies and were alarmed that their baby was to return there. They had understandably become dependent on the technology of the specialised unit and had formed strong relationships with members of staff. They felt let down. Staff also find this difficult.

\section{The baby goes home}

Anticipation of taking the baby home was talked about with a mixture of joy and anxiety. The removal of the last monitor was hard to accept, and fears of cot death were often discussed. Some parents wanted to take an apnoea alarm home and a few became angry when the doctors decided that this was not appropriate. Many parents were nervous at the prospect of looking after their baby at home. They were worried about feeding, keeping the baby warm, infections, vaccinations, and in particular how much their general practitioner and health visitor would know about premature infants. In Nottingham the community midwife attending the meetings provided valuable continuity between the hospital and the community. At St George's a few parents attended meetings by invitation after they had taken their babies home and were able to give good practical advice and reassurance.

\section{Discussion}

Self-help groups have increased in recent years ${ }^{4}$ and are now found in several areas of paediatrics. Groups for parents of 
babies in neonatal units have been reported in the United States $^{5-7}$ and Canada ${ }^{8}$ but not previously in Britain. An evaluation of a group in Toronto showed that parents who attended such groups were more concerned with their babies both while in hospital and after they returned home.

Our original aims were partly fulfilled. Many parents have attended and found the meetings helpful and supportive. Some quickly became more confident-for instance, picking up their baby for the first time directly after a meeting. Communication has increased among parents both during the meetings and at other times. Some couples even said that they were able to talk more freely between themselves. Parents who did not come to meetings merit special attention. Single mothers may have felt out of place as most people came as a "couple" and discussed joint experiences. On a few occasions several single mothers attended together and thereby gained support. Parents who speak little English obviously found group discussion difficult. Those whose infants were likely to be handicapped or die nearly always stayed away. The possibility of handicap or death must be a major anxiety for most parents but was seldom discussed. Although few parents attended during the first week or when their infant was critically ill, many were able to talk about it later. Sharing experiences helped parents to realise that they were not alone and that their feelings were normal and valid.

Staff members have gained greater insight into the parents' anxieties and problems. The meetings have shown many areas for concern about the way in which parents are treated. We have been able to make some changes-for example, staff on the antenatal ward at St George's have started a support group for parents; mothers with babies in the neonatal unit will be grouped together on the postnatal ward in Nottingham. One of our main difficulties has been to find the time and opportunity to communicate what we have learnt in the group to other professionals concerned with the parents and babies both in the hospital and in the community. If new insight is to result in changes that benefit the parents their views must be made known and taken into account when policy decisions are made.

Some individual needs have been highlighted during the meetings-for instance, problems with finance, housing, other children, and employment. Parents who have particular difficulties in relating to their babies and those who are extremely anxious or distressed have often shown this in meetings, and we have been alerted to their need for additional support.

\section{Conclusion}

These two neonatal units have many differences but our experiences of holding meetings for parents over the past 18 months has been so similar that a joint report is possible. In recent years progress in neonatal intensive care has been rapid. As more expertise and technology is brought to bear on the physiological needs of very small infants it behoves us to consider the needs of the parents whose babies we care for. Parent meetings must never replace individual communication between parents and staff but can provide useful additional support for parents at a very stressful time. We suggest that they could be run with benefit to both parents and staff in other neonatal units.

We wish to acknowledge fellow colleagues who run the meetings: Tina Eldridge, Margaret Hunt, Bernadette Khan, Peter Crowther, Ann Liversey, Corrie van de Linden, Mike Watkinson, Liz Lound, Jean Fletcher, Martina McGovern, Jane Trasler, Margaret Ball, Anne Coleman, and Rosemarie Haddon. We would also like to thank Dr Nicholas Rutter, Mrs Paula Hale, Dr Neil McIntosh, and the many other members of staff who have given us their help and support throughout.

Requests for reprints to Dr Neil McIntosh, Department of Child Health, St George's Hospital, Blackshaw Road, London SW17 0QT.

\section{References}

${ }^{1}$ Baldwin JA, Oliver JE. Epidemiology and family characteristics of severely abused children. Br F Prev Soc Med 1975;29:205-21.

${ }^{2}$ Ambuel J, Harris B. Failure to thrive: a study of failure to grow in height or weight. Ohio Med f 1963;59:997-1001.

${ }^{3}$ Shaheen E, Alexander D, Truskowsky M, Barbero GJ. Failure to thrivea retrospective profile. Clin Pediatr 1968;7:225-61.

4 Robinson D. Self help groups. Br f Hosp Med 1978;20:306-11.

${ }^{5}$ Enriques M, Harrell H, Putman M. Role of parent groups for an intensive care nursery. In: Sell EJ, ed. Follow-up of the high risk newborn-a practical approach. Springfield: C C Thomas, 1980.

${ }^{6}$ Erdman D. Parent-to-parent support: the best for those with sick newborns. Maternal Child Nursing 1977;Sep/Oct:291-2.

${ }^{7}$ Mangurten HH, Slade C, Fitzsimmons D. Parent-parent support in the care of high-risk newborns. $7 O G N$ Nurs 1979;8:275-7.

${ }^{8}$ Minde K, Shosenberg N, Marton P, Thompson J, Ripley J, Burns S. Self-help groups in a premature nursery-a controlled evaluation. $\mathcal{f}$ Pediatr 1980;96:933-40.

(Accepted 1 fuly 1982)
Clinical curio: Sleep phobia after awareness during general anaesthesia: treatment by induced wakefulness

A mother suffered from recurrent nightmares, and difficulty in going to sleep, after experiencing awareness during general anaesthesia for caesarean section. Bronchospasm had occurred immediately after induction and endotracheal intubation. The patient remembered waking after she had gone to sleep and hearing the anaesthetist's utterances about her blue colour. She felt the pain of the incision. After a while the pain went but she could still feel the surgeons working. She thought she had "had it" and could not move to tell anyone. Thereafter she feared going to sleep. Lying on her back produced a sinking feeling and a sense of panic. When she did sleep she was likely to wake up from a nightmare in which she could not breathe. Hypnosis improved this condition, but her symptoms continued to cause disability.

Six years later the patient needed a minor operation and was referred for advice. At interview, recalling her experience and its after effects produced some catharsis. For her forthcoming minor operation she was offered the opportunity of undergoing a general anaesthetic, with a muscle relaxant, during which she would deliberately be rendered wakeful. She would be able to communicate only with her right hand. Her right forearm would be isolated from the muscle relaxant by a pneumatic tourniquet. This time she would not be a blue colour, and she would be holding the hand of an anaesthetist who was reassuring her. She accepted these proposed anaesthetic manoeuvres in the hope that her sleep disturbances and nightmares might be eliminated. During the anaesthetic the patient became wakeful when inspiring halothane $0.5 \%$ and when the nitrous oxide had been reduced to $20 \%$. Her right-hand movements came under her control, and she was able to signal that she was physically comfortable. After further reassurance and suggestion the anaesthetic was deepened and the operation began. Shortly after recovery from the anaesthetic the patient was wreathed in smiles and stated that she had had a lovely sleep, with no memory of being awake at any time during the anaesthetic or of dreaming. That evening and the next day she felt better. Her happy postoperative state contrasted appreciably with her preoperative state. Four months later she had had no recurrence of her nightmares, her husband had told her that her personality was back to normal, and she could lie on her back without a sinking feeling and a sense of sheer panic. Occasionally there was still a slight sense of panic on retiring, but she would just read a book and then go happily off to sleep.

Reliving the trauma was akin to abreaction. The confrontation with the dreaded situation under circumstances in which the anxiety was removed can also be seen as flooding. It was essential to lighten the anaesthesia sufficiently to allow the patient to orientate, exert selfcontrol, and communicate clearly. Without clear communication combined with good rapport and trust there could have been additional trauma and a further deterioration in her condition.M E TUNSTALL, consultant anaesthetist, and I M LOWIT, consultant psychiatrist, Aberdeen. 